\title{
Genome sequencing and comparative genomic analysis of highly and weakly virulent strains of Sclerotium rolfsii, the causal agent of peanut stem rot
}

\section{Liying Yan}

Oil Crops Research Institute Chinese Academy of Agricultural Sciences

Zhihui Wang

Oil Crops Research Institute Chinese Academy of Agricultural Sciences

Wanduo Song

Oil Crops Research Institute Chinese Academy of Agricultural Sciences

\section{Pengmin Fan}

Oil Crops Research Institute Chinese Academy of Agricultural Sciences

\section{Yanping Kang}

Oil Crops Research Institute Chinese Academy of Agricultural Sciences

\section{Yong Lei}

Oil Crops Research Institute Chinese Academy of Agricultural Sciences

\section{Liyun Wan}

Jiangxi Agricultural University

\section{Dongxin Huai}

Oil Crops Research Institute Chinese Academy of Agricultural Sciences

\section{Yuning Chen}

Oil Crops Research Institute Chinese Academy of Agricultural Sciences

\section{Xin Wang}

Oil Crops Research Institute Chinese Academy of Agricultural Sciences

\section{Hari Sudini}

International Crops Research Institute for the Semi-Arid Tropics

Boshou Liao (D liaoboshou@163.com )

Oil Crops Research Institute Chinese Academy of Agricultural Sciences

\section{Research article}

Keywords: Peanut, Sclerotium rolfsii, PacBio Sequel sequencing, Pathogenesis-related genes, Comparative genomic analysis 
Posted Date: July 2nd, 2020

DOl: https://doi.org/10.21203/rs.3.rs-38224/v1

License: (c) (i) This work is licensed under a Creative Commons Attribution 4.0 International License. Read Full License

Version of Record: A version of this preprint was published at BMC Genomics on April 16th, 2021. See the published version at https://doi.org/10.1186/s12864-021-07534-0. 


\section{Abstract \\ Background}

Stem rot caused by Sclerotium rolfsii is a very important soil-borne disease to peanut worldwide. S. rolfsii is a necrotrophic plant pathogenic fungus with an extensive host range and worldwide distribution. It can infect peanut stems, roots, pegs and pods, leading to varied yield losses. S. rolfsii strains GP3 and ZY collected from peanut in different provinces of China exhibited significant difference in virulence on peanut by artificial inoculation test. In this study, de-novo genome sequencing of these two distinct strains was performed in the hopes of revealing the genomic basis of virulence differentiation.

\section{Results}

Scleotium rolfsii strains GP3 and ZY, with weak and high virulence on peanut, respectively, exhibited similar growth rate and oxalic acid production in laboratory. The genomes of $S$. rolfsii strains GP3 and ZY were sequenced by Pacbio long read technology and exhibited $70.61 \mathrm{Mb}$ and $70.51 \mathrm{Mb}$, with contigs of 27 and 23, and encoded 17,097 and 16,743 putative protein genes, respectively. Comparative genomic analysis revealed that the pathogenicity-related gene repertoires, which might be associated with the virulence, diverged between GP3 and ZY. Detailed analysis further revealed 58 and 45 unique pathogenhost interaction $(\mathrm{PHI})$ genes in GP3 and $\mathrm{ZY}$, respectively. The $\mathrm{ZY}$ strain had more carbohydrate-active enzymes (CAZymes) in its secretome than GP3, especially in the glycoside hydrolase family (GH), the carbohydrate esterase family (CBM), and the polysaccharide lyase family (PL). GP3 and ZY also had different effector candidates. These results indicated that differences in PHI, secreted CAZymes, and effectors may play important roles in virulence differentiation between these two strains.

\section{Conclusions}

The data provided a further understanding of the $S$. rolfsii genome. Detailed comparative genomic analysis provided clues into the genomic basis of its necrotrophic lifestyle and virulence diversification.

\section{Background}

Sclerotium rolfsii is a destructive soil-borne fungal pathogen. Its sexual stage, Athelia rolfsii, belongs to Basidiomycota and rarely occurs in nature; thus, its role in the life cycle of the fungus is unknown [1]. $S$. rolfsii infects more than 600 plant species, especially economically important agricultural and horticultural crops including peanuts, soybeans, wheat, cotton, tomatoes, potatoes, cucurbits, and onions $[2,3]$, and is thus a pathogen of wide importance. Moreover, S. rolfsii produces sclerotia, which plays a key role in the disease cycle and has the ability to survive in soil for long periods [4]. In peanut (Arachis hypogaea), S. rolfsii can infect stems, roots, pegs, and pods and causes plant yellowing, branch wilting, and even entire plant wilting. Peanut stem rot caused by $S$. roflsii is also known as southern stem rot, 
southern blight, white mold, and Sclerotium rot [5]. This fungal disease has been reported in most peanut producing regions in the world. Loss caused by peanut stem rot estimated at 41 million US dollars in Georgia in 2011[6]. Up to $30 \%$ yield loss were recorded in farmers' field in India [7]. Peanut stem rot has been epidemic in China recently, caused up to $50 \%$ yield loss in hotspots, and was the most serious soilborne fungal disease in peanut [8].

Control of peanut stem rot disease is difficult because of wide range of hosts, profuse mycelium, abundant persistent sclerotia, and genetic variability of populations of $S$. rolfsii [4]. Currently, there are only a few resistant commercial peanut cultivars available for use [9-11]. Limited success was achieved in developing resistant varieties to peanut stem rot in China [12]. Normally, approaches to control S. rolfsii on peanuts include the application of fungicide and agronomic measures such as rotation with non-host crops or coverage of infected crop debris with deep plowing [13]. But these methods are still not enough for effective control of this disease.

In order to implement effective integrated management practices to control $S$. rolfsii on peanuts, knowledge about the genetic basis of differently virulent strains of $S$. rolfsii is a key component, as it is essential for host resistance assessment in a given region [14]. Earlier investigators observed differences in virulence among isolates of $S$. rolfsii in the USA and India [15-18]. They were classified as highly, moderately, and weakly virulent strains [16]. Until now, differences in virulence have not been reported among $S$. rolfsii strains in China. In previous research, virulence of $S$. rolfsii strains was found to be highly correlated with endo-PG production and growth rate [16], but the genetic basis of virulence was still unknown.

The genetic variability of $S$. rolfsii stains has not been documented. Correlations between pathogenic traits and genetic patterns have rarely been identified. To gain the relevant insights, we sequenced two $S$. rolfsii strains isolated from peanuts in different provinces of China. The two strains possessed similar cultural morphology and growth rate on PDA media but demonstrated different levels of virulence to peanut in inoculation tests. The ZY strain had high virulence, and the GP3 strain had weak virulence. The two strains were also similar in oxalic acid production in vivo. To decipher the basis of differences in virulence, comparative genomic analysis was conducted between these two strains. This study will be meaningful for further identifying determinants of pathogenicity as well as deepening understanding of S. rolfsii infection mechanisms.

\section{Results}

\section{Divergent virulence}

The typical symptoms caused by these two strains on the peanut stems included unrestricted lesions on infection sites followed by tissue maceration and finally wilting. Disease severity was scored at $14 \mathrm{dpi}$ and showed significant differences between these two strains. The disease index of ZY was 82.34, which was classified as highly virulent. The disease index of GP3 was 32.2, which was regarded as weakly 
virulent (Fig. 1a, 1b). The growth rate of these two strains was similar on PDA and showed no significant difference (Fig. 1C, 1d). There was no significant difference in the amount of oxalic acid (OA) produced by these two strains. OA was analyzed using the haloes revealed on the PDA containing bromophenol blue, and by the $\mathrm{OA}$ amount in the culture filtrate as analyzed by $\mathrm{KMnO}_{4}$ titration after grown in PDB without shaking for 7 days (Fig. 1e, 1f).

\section{Genome sequence and assembly}

Genome sequencing of GP3 and ZY was performed using the long-read PacBio Sequel technology. High coverage ( $92.33 \mathrm{X}$ for GP3 and $142 \mathrm{X}$ for ZY, respectively) PacBio subreads were assembled de novo using CANU [19]. Then, the assembled genomes were corrected by aligning subreads using the Arrow program with the default parameter. Finally, Pilon [20] was used to polish the resulting assemblies with Illumina data ( $6.42 \mathrm{~GB}$ for GP3 and $7.03 \mathrm{~GB}$ for ZY). The base accuracy of the assemblies was estimated by Illumina reads alignment. The assembled genomes of GP3 and ZY were $70.51 \mathrm{Mb}$ and $70.61 \mathrm{Mb}$, respectively. The assemblies contained 27 contigs with an N50 length of $3.67 \mathrm{Mb}$ for GP3, and 23 contigs with an N50 length of $3.71 \mathrm{Mb}$ for ZY (Table 1). The two strains had genome assemblies of a similar size, both slightly smaller than that of $S$. rolfsii Indian strain M10 (73.18 Mb). In comparison with other phytopathogenic species of Basidiomycota, the $S$. rolfsii strains' genomes were larger than those of Rhizoctonia solani AG1-1A (36.93 Mb) [21] and Ustilago maydis (19.61 Mb) [22], but smaller than those of Puccinia granimins (88.72 Mb) [23] and Melampsora laricipopulina (97.68 Mb) [23]. The integrity of the genome assemblies was assessed using BUSCO [24]. About $97.5 \%(1301 / 1335)$ and $97.2 \%$ $(1298 / 1305)$ of gene groups required for the correct assembly of Basidiomycota were present in GP3 and ZY, respectively (Figure S1). The genomes of $S$. rolfsii strains GP3 and ZY were deposited in GenBank under BioProject numbers: PRJNA635225, PRJNA635226, and BioSample numbers: SAMN15029893, SAMN15029894, respectively.

The average GC contents of the resulting S. rolfsii genomes of GP3 (46.27\%) and ZY (46.29\%) were comparable to $S$. rolfsii M10 (46.16\%). The GC content of $S$. rolfsii strains was remarkably low compared to that of $U$. maydis (53.80\%) and $R$. solani AG-1A (47.60\%). Interestingly, they were similar to related fungi species in Agaricomycetes, such as Moniliophthora roreri (46.20\%) [25], Piloderma croceum (46.30\%) [26], and Psilocybe cyanescens (46.10\%) [26], suggesting that similar GC content may be a general genomic feature of this class within the Agaricomycetes.

Gene candidates in the S. rolfsii GP3 and ZY genomes were predicted by a combined approach, and 17,097 and 16,743 genes with an average gene length of 2,013.91 bp and 2,039.76 bp were identified respectively (Table 1). Approximately $93.27 \%(15,947)$ of GP3 genes and $93.93 \%(15,727)$ of ZY genes could be annotated by non-redundant nucleotide and protein sequences in the Cluster of Orthologous Groups (KOG), Gene Ontology (GO), Kyoto Encyclopedia of Genes and Genomes (KEGG), Non-redundant Protein (NR), and Swiss-Prot databases (Figure S2-5). The number of genes predicted in S. rolfsii strains GP3 and ZY was similar to that in S. rolfsii strain M10 (16,830 genes), but less than that in other fungi species in Agaricomycetes with similar genome size, such as the Gymnopus luxurians genome 
(65.22 Mb) [26] with 22,395 genes and the Pisolithus tinctorius genome (61.58 Mb) [26] with 22,845 genes.

In this study, we identified 356 tRNAs and 48 rRNAs in the S. rolfsii GP3 genome, and 415 tRNAs and 55 rRNAs in the $S$. rolfsii ZY genome (Table S1). The number of tRNAs was similar to that of G. luxurians (359) and much larger than that of $P$. tinctorius (195) [26]. The same number of snRNAs was identified in both GP3 and ZY genomes. GP3 and ZY shared a similarly low number of unique genes with 75 for GP3 and 37 for ZY distributed in 62 and 19 gene families (Table S2), respectively. These two S. rolfsii strains were highly similar to pairs of orthologs sharing on average $99.96 \%$ identity at the protein level $(99.95 \%$ at the nucleotide level). Sequence comparison between two whole-genome assemblies of S. rolfsii GP3 and ZY revealed high genomic collinearity (Fig. 2). The results suggested that the two strains are closely related.

\section{Repetitive element analysis}

De novo and homology approaches were combined to identify repetitive sequences in the S. rolfsii GP3 and $Z Y$ genomes. A total of $14.75 \%$ and $14.66 \%$ repetitive sequences were generated for GP3 and $Z Y$, respectively (Table 1, Table S3). The abundance of repetitive sequences was similar between these two strains and much more than that of $S$. rolfsii strain MR10 [27], which had a repetitive sequence content of $3.73 \%$. GP3 and ZY contained repetitive elements including DNA transposons, retroelements, and satellites. Retroelements were abundant in the studied genomes, accounting for $10.28 \%$ and $10.79 \%$ in GP3 and ZY, respectively. LTR was abundant in the retroelements, accounting for $9.85 \%$ and $10.38 \%$ in GP3 and ZY, respectively (Fig. 3, Table S4).

\section{Orthology analysis and phylogenetic analysis}

The entire sets of predicted proteins of S. rolfsii GP3 and ZY were clustered with the OrthoMCL program [28] to identify gene families. Comparative analysis of the genomes of related species of Agaricomycetes, Basidiomycota showed that $S$. rolfsii strains had larger genomes but fewer total genes in comparison to most of the other species (Figure S6). It was supposed that $S$. rolfsii strains may undergo genome expansion during evolution. Of these families, the unclustered gene numbers of GP3 and ZY were the least among fungi in Agaricomycetes. A Venn diagram of the OrthoMCL revealed that $S$. rolfsii strains shared 4813 genes with other four Agaricomycetes species (Fig. 4a).

To understand the genetic relationship of GP3 and ZY to the related Agaricomycetes species, we generated a phylogenetic tree of single-copy genes based the orthologous gene family analysis between two S. rolfsii strains and other Agriocomycetes fungi, including Armillaria gallica, Auricularia subglabra [29], Exidia glandulosa [30], Galerina marginata, G. luxurians, Hydnomerulius pinast [26], P. cyanescens, Scleroderma citrinum [26], and Piloderma croceum [26]. The resulted phylogenetic tree indicated that $S$. rolfsii strains were more closely related to E. glandulsa and A. subglabra, which belonged to Auriculariale, than to $P$. croceum, which belonged to Atheliaceae, the same as S. rolfsii (Fig. 4b).

\section{Genes involved in pathogenicity}




\section{Homologs in PHI base}

In total, we identified 4,600 and 4,603 potential pathogen-host interaction (PHI) genes belonging to 995 and 991 gene families (Fig. 5a). "Virulence" category was dominant in PHI genes, followed by "Pathogenicity" type (Fig. 5b). Compared with S. rolfsii GP3, a total of 45 PHI genes were unique in ZY, 13 of which belonged to category of "reduced virulence". Besides these unique PHI genes, several PHI genes exhibited great expansion in the ZY genome. For instance, ZY contained more PHI 211 and PHI 2020 genes than GP3. We also found $58 \mathrm{PHI}$ genes in GP3 were not present in the ZY genome, 12 and 18 of which belonged to categories of "loss of pathogenicity" and "reduced virulence", respectively (Table S5).

\section{CAZymes}

Plant cell wall carbohydrates formed a complex network of different polysaccharides that are subdivided in cellulose, hemicellulose, and pectin. These polysaccharides, together with others, are targets of the carbohydrate-active enzymes (CAZyme) that degrade them into simple monomers that can be used as nutrients. The genomes of $S$. rolfsii GP3 and ZY contained 957 and 925 genes encoding putative CAZymes, distributed in 118 and 119 CAZyme families, respectively. The CAZyme content of GP3 was slightly larger than that of ZY, and CAZyme content of both GP3 and ZY was more than that of $S$. rolfsii MR10 (902). Glycoside hydrolases (GH) were dominant in the GP3 and ZY genomes (51.62\% and 52.54\%, respectively), followed by carbohydrate-binding modules (CBMs) and glycosyltransferases (GTs) (Fig. 6a).

Comparison of CAZyme content of $S$. rolfsii strains with other plant pathogens including six saprotrophic fungi (Aspergillus niger, Bortytis cinerea, Pecillium digitatum, Sclerotinia sclerotium, R. solani, and Verticillum dahliae), three hemitrophic fungi (Colletotrichum higginsianum, Fusarium granimearum, and Magnaporthe oryzae), and three biotrophic fungi (P. granimis, Peronospora effusa, and U. maydis), to determine whether the life style of these fungi correlated with their CAZyme content and distribution. The CAZyme content of $S$. rolfsii genome was the highest among above pathogens analyzed (Fig. 6b). Necrotrophic fungi had more CAZymes than biotrophic and hemibiotrophic fungi. In comparison with other necrotrophic plant pathogens with a broad host range, such as S. sclerotinia, B. cinema, and $V$. dahliae, the CAZyme content of $S$. rolfsii was three times as much as these fungi. Compared to Basidiomycota plant pathogens, CAZyme content of $S$. rolfsii was also three times as much as $R$. solani and $P$. graminis, and four times as much as U. maydis. The high expansion of CAZymes in S. rolfsii suggested that CAZymes might play an important role in making nutrients accessible for $S$. rolfsii growth and may be a cause of its broad host range. Besides differences in CAZyme content, the number of CAZymes involved in cellulose, hemicellulose, and pectin degradation of S. rolfsii strains GP and ZY was also different from that of other pathogens analyzed (Tables S6-S8). The number of those CAZymes in $S$. rolfsii strains was noticeably larger than that in other pathogens analyzed, especially in the pectin degrading capacity. This suggested that cellulose, hemicellulose, and pectin-degrading enzymes expanded in the $S$. rolfsii genome compared to other pathogens. The S. rolfsii genomes investigated thus far harbored the largest number of carbohydrate-active enzymes, which suggested one possible reason 
that the Sclerotium genus succeeded as a necrotrophic fungus, namely, that $S$. rolfsii has a powerful capacity to break down the defense of plant cell walls and infect its hosts.

Glycoside hydrolases are known to catalyze the hydrolysis of glycosidic bonds in carbohydrate molecules. S. rolfsii was enriched in one glycosyl hydrolase family, $\mathrm{GH} 28$, a class of polygalacturonases involved in pectin degradation. The amount of GH28 was the same in GP3 and ZY (62 vs 62) and was significantly larger than the amount found in the other pathogen species analyzed (Table S8). The expansion of $\mathrm{GH} 28$ was not found in the biotrophic and some hemibiotrophic pathogens, such as $U$. maydis, P. graminis, and M. oryzae. Generally, necrotrophic plant pathogens possess more $\mathrm{GH} 28$ enzymes than biotrophic and non-pathogenic fungi [32]. In comparison with the other necrotrophic pathogenic fungi analyzed, S. rolfsii strains had three times more $\mathrm{GH} 28$ than others. Besides $\mathrm{GH} 28$, other glycoside hydrolases involved in pectin degradation in S. rolfsii, such as GH35, GH51, and GH78, also expanded in comparison to other pathogen species.

\section{Secretome and effector}

To establish a successful infection and evade plant defense responses during colonization, plant pathogens secrete proteins and other molecules, collectively termed effectors, to various host compartments $[33,34]$. A subset of secreted proteins from pathogens is expected to determine the progress and success of the infection [35].

Secretory proteins play crucial roles during the early infection of pathogenic fungi. The putative secreted proteins of $S$. rolfsii GP and ZY were identified based on a comprehensive pipeline (Figure S7). The genomes of GP3 and ZY were predicted to encode 536 (3.14\%) and 551 (3.29\%) secreted proteins, respectively. In relation to Basdiomycota pathogens, $S$. rolfsii had a smaller secretome than that of $R$. solani AG1 (9.17\% of the proteome), and those of Puccinia (6.4\%) [36] and Ustilago (6.2\%). In general, necrotrophs that thrive on dead or dying plant cells encode high numbers of secreted proteins, but this phenotype did not appear in S. rolfsii GP3 and ZY.

The CAZyme content of $S$. rolfsiiGP3 was larger than that of ZY as above mentioned, but the CAZyme content in the secretome of GP3 (30) was much less than that in ZY (151) (Fig. 6c, Table S9). Moreover, some CBMs and polysaccharide lyase (PL) families, which putatively degrade cellulose and hemicellulose, were found in the ZY secretome but not in GP3. In addition, ZY had more secreted GHs (113), which degrade cellulose, hemicelluloses, pectin, and CE, than GP3 (20) (Fig. 6d). The differences in CAZyme content in the secretome could provide clues to unravel the difference in virulence between $S$. rolfsii GP3 and ZY.

Effector proteins have been observed to be secreted by several necrotrophic microbial pathogens [37] and induce disease in their hosts. A total of 50 and 46 putative effector candidates for GP3 and ZY, respectively, were predicted by Effector P.1. After manual inspection and removal of candidates with known plant cell wall degrading catalytic domains, including CAZymes, peptidase, lipase, and peptidases, and with the criteria of $50 \leq$ molecular weight $\leq 300 \mathrm{kDa}, 0-1$ predicted trans-membrane domain, and $\geq$ 
4 cysterine residues, a total of 20 and 19 effector candidates for GP3 and ZY were identified (Table 2), respectively. Most of the putative effector candidates were small (average length of 170 and 139 amino acids, ranging from 121 to 278 , and 58 to 272 amino acids for GP3 and ZY, respectively). These candidates were rich in cysteines (the average cysteine composition was $9.11 \%$ (GP3) and $8 \%(Z Y)$ ). Most of the effector candidates ( $60.0 \%$ and $73.7 .1 \%$ of GP3 and ZY) with function were unknown, respectively. A total of $15.0 \%$ of these candidate proteins had no hits in the NR database. The function of these predicted effectors needs to be further verified in future research.

\section{Discussion}

Sclerotium rolfsii is a very important necrotrophic plant pathogen with a broad host range. To date, only one strain's genome has been sequenced, and there is little information on its virulence [27]. In the present study, we discovered two $S$. rolfsii strains that differed in virulence in peanuts after inoculation. These strains did not show significant differences in growth rate and oxalic acid production. Therefore, we conducted genome sequencing of the two $S$. rolfsii strains and produced gapless high-quality genomes in hope of unraveling the genomic basis underlying the differences in virulence between the two strains.

During pathogenesis, $S$. rolfsii may produce cell wall degrading enzymes such as endo-polygalacturonase (endo-PG) [38, 39], cellulose [40], and polymethylagalacturonase [16] in conjunction with oxalic acid [38, 16]. Bateman and Beer [38] suggested that oxalic acid, pectinase, and cellulase act synergistically in the destruction of host tissue by $S$. rolfsii. Secretion of oxalic acid and endo-PG concomitantly with rapid mycelial growth appeared to be the key requirement for establishing infection [16]. Earlier investigators observed differences in virulence among isolates of $S$. rolfsii $[16,41,42]$ and found that virulence was highly correlated with endo-PG production and growth rate, provided a base level of oxalic acid was produced [16]. S. roflsii is renowned for its ability to acidify its environment through the secretion of organic acids. OA was reported to have a positive correlation to the virulence of $S$. roflsii isolates [42]. In contrast, OA was found to be not correlated with the virulence of $S$. rolfsii by Punja (1985) [16], who found that highly, moderately, and weakly virulent strains all produced similar amounts of oxalic acid. To investigate whether oxalic acid played an important role on virulence differentiation in $S$. rolfsii strains GP3 and ZY, we tested these two strains on the PDA plate containing bromophenol blue and measured the amount of OA produced in a liquid PDB medium by $\mathrm{KMnO}_{4}$ titration. The results indicated that there was no significant difference in oxalic acid production between the weakly virulent strain GP3 and the highly virulent strain ZY, although oxalic acid is an essential virulence factor for S. s/cerotiotum [43]. S. rolfsii produced a basic level of oxalic acid to acidic environment that facilitates the optimal activity of certain sets of cell wall degrading enzymes and peptidases, it was not the key factor for virulence differentiation between S.rolfsii GP3 and ZY.

Plant cell walls are an important barrier that plants use to protect themselves from attacking by a range of organisms. Plant cell wall carbohydrates form a complex network of different polysaccharides that can be subdivided into three categories: cellulose, hemicellulose, and pectin. Plant pathogenic fungi employ diverse gene repertoires, including carbohydrate-active enzymes (CAZymes), to invade host plants 
and subvert host immune systems $[44,45]$. CAZymes are known to play an important role in hostpathogen interactions and, along with effectors, are prime targets for studying virulence factors in fungi $[46,47]$. CAZyme families with potential roles in virulence were examined in detail in S. rolfsii strains GP3 and ZY. In our study, the CAZyme content in weakly virulent strain GP3 was found to be slightly more than that in highly virulent strain ZY. GP3 also had a noticeably higher number of enzymes in the AA, CBM, CE, and GH families (Table S11). GP3 and ZY had a similar number of enzymes involved in cellulose, hemicellulose, and pectin degradation (Table S12), these results indicated that CAZyme content was not related to the difference in virulence between S. rolfsii GP3 and ZY. We then undertook further analysis of the secreted CAZymes, which were involved in plant cell wall or fungal cell wall degradation and played an important role in phytopathogenic penetration of their hosts [48]. There was a significant difference in the levels of secreted CAZymes between GP3 and ZY. Highly virulent strain ZY possessed three times more secreted CAZymes (105) than weakly virulent strain GP3 (30). ZY also possessed more enzymes involved in pectin degradation, such as $\mathrm{GH} 28$. These results indicated that secreted CAZymes, especially polygalacutronases, may play an important role in virulence differentiation between $S$. rolfsii strains. This was in accordance with the results of Punja (1985) [16] who reported that the virulence of $S$. rolfsii was highly correlated with endo-PG production.

To establish infection, fungal plant pathogens secrete effector molecules that manipulate host physiology, including immune responses that are triggered when plant hosts sense invading pathogens [49-51]. Effectors have been discovered in multiple plant pathogenic fungi and exhibit numerous different functions depending on fungal lifestyle. Necrotrophic fungi, which require dead tissue on which to feed, often produce effectors that promote cell death, whereas biotrophic fungi, which require living tissue, produce effectors that prevent cell death [52-55]. In some soil-borne vascular necrotrophic pathogens that infect a broad range of host plants, effectors involved in virulence have been identified. In S. sclerotiorum, about 70 effectors have been identified [56], a small, cysteine-rich secreted protein with a cyanoviron-N homology (CVNH) domain, attenuated virulence when deleted [57]. A total of 127 putative effectors were identified in another broad host range necrotrophic pathogen $V$. dahliae VdLs17 strain [58]. Among them, the Vd2LysM effector was reported to contribute to host-specific virulence [59], and VdCP1 contributed to virulence and triggered the host plant's immune system [60]. Up to now, little experimental evidence for the existence of similar effector proteins was available for $S$. rolfsii. To identify putative effectors involved in virulence, we searched the whole proteome of $S$. rolfsii and found that the effectors of GP3 and ZY were completely different. S. rolfsii existed as a multi-nuclear heterokaryon, in which individual cells may carry multiple nuclei. The method for the stable transformation of $S$. rolfsii has not been available yet, and thus functional testing of pathogenic candidate genes in further studies will be challenging.

Despite the variety of pathogenicity-related mechanisms involved, accumulating evidence indicates that necrotrophic plant pathogens interact with their hosts in a manner much more subtle than originally considered and that signaling between them plays a significant role in the lifestyle of these pathogens [61]. The mechanism of differences in virulence is complicated in plant pathogens. Besides secreted CAZymes and effectors that participate in virulence, other factors may also be involved in virulence to 
host plants. It was reported that the genomic islands might contribute to the expanded genetic diversity and virulence of $V$. dahliae [62]. Virulence-associated effectors were often found to have been affected by both repeat activity and repeat-induced point mutations (RIP) in Leptosphaeria maculans and $S$. sclerotiorum $[63,64]$.

This work has provided important clues to factors involved in virulence differentiation among these two $S$. rolfsii strains. The data presented here will provide a useful foundation for further studies to explore the basis for pathogenesis, with the goal of understanding the mechanism of $S$. rolfsii infection.

\section{Conclusions}

We generated long-read PacBio reads and gapless genome assemblies of two $S$. rolfsii strains with different levels of virulence to peanut and then implemented a comparative genomic analysis of these strains. The genome of $S$. rolfsii encoded a high number of cell wall-degrading enzymes. The high number of genes of these categories most likely reflects the saprophytic lifestyle of $S$. rolfsii, which commonly feeds on the dead organic matter of plant origin. The obtained GP3 and ZY genome assemblies and annotation represent the few available Sclerotium genome resources for studying the pathogenic mechanism of this fungus toward peanut plants.

\section{Methods}

\section{Isolates and oxalic acid production}

Scleotium rolfsii strains ZY and GP3 were originally collected from Henan and Guangxi provinces of China, respectively. These two strains were in different mycelial compatibility group (MCG) and exhibited similar growth rate on potato dextrose agar (PDA medium: $200 \mathrm{~g}$ peeled and sliced potatoes boiled for $20 \mathrm{~min}, 20 \mathrm{~g}$ dextrose, adjusted to $\mathrm{pH} 7.0,20 \mathrm{~g}$ agar, to make the final volume $1000 \mathrm{ml}$ with distilled water) [65]. Oxalic acid production of $S$. rolfsii was detected by two methods. PDA containing bromophenol blue was used to test oxalic acid produced in PDA plate. Mycelium discs of each strain were placed in the center of PDA medium containing $0.5 \mathrm{~g} / \mathrm{l}$ of bromophenol blue and kept at $30^{\circ} \mathrm{C}$ in the dark, four petri dishes for each strain. The diameter of yellow halo was measured after three days. $\mathrm{KMnO}_{4}$ titration was used to detect oxalic acid produced in liquid PDB. The strains grew in liquid PDB medium, three replicates of $150 \mathrm{ml}$ flasks containing $30 \mathrm{~mL}$ of medium were included for each isolate, three discs per flask were added and the flasks were incubated without shaking at $30^{\circ} \mathrm{C}$ in the dark. The culture of each strain was filtered through a Whatman No.1 filter paper after 5 days incubation. Oxalic acid (OA) content in $5 \mathrm{~mL}$ filtrate was determined using a $\mathrm{KMnO}_{4}$ titration method following the procedure of Kritzman's [66].

\section{Pathogenicity test}

The experimental design was a randomized complete block with three replications. Plots consisted of three rows with a row length of $2.5 \mathrm{~m}$ and row space of $0.33 \mathrm{~m}$. The peanut variety Zhonghua 21 was 
planted in all trials (15 plants per row) in plots. The plants were inoculated $50-55$ days after sowing. $S$. rolfsii inoculum was prepared just before inoculation. Oat grains were soaked in water for $4 \mathrm{~h}$, sterilized at $121^{\circ} \mathrm{C}$ for 30 min twice after water removed. The fresh mycelium discs of S. rolfsii GP3 and ZY were transferred to the flasks containing sterilized oat grains, respectively. The oat grains culture maintained in the dark at $30^{\circ} \mathrm{C}$ until surface of grains covered by $S$. rolfsii mycelium. The oat grains inoculum was mixed with equal amount of sterilized sand to ensure uniform delivery of inoculum. Each plant was inoculated with $2 \mathrm{~g}$ of $S$. rolfsii oat inoculum and sand mixture. The plots were watered to field capacity after inoculation. Disease symptoms were investigated 14 days after inoculation. A 1-5 scale for the severity of wilting according to Shokes' method [67], where $1=$ no symptom, 2 = lesions on stem only, $3=$ up to $25 \%$ of the plant wilting, $4=26-50 \%$ of the plant wilting, and $5=>50 \%$ of the plant wilting. Disease index was calculated by using the following formula. $\mathrm{DI}=\{[\Sigma$ (number of plants $\times$ corresponding diseases scale)] / (total number of plants $\times$ maximum disease scale) $\} \times 100$. Different level of virulence was determined according to Punja (1985) [16], high virulence with DI more than 66.7, and weak virulence showing DI less than 33.3.

\section{DNA and RNA purification}

To prepare the genomic DNA and RNA for sequencing, the GP3 and ZY isolates were cultured on PDA plates overlaid by cellophane films and maintained in the dark at $30^{\circ} \mathrm{C}$ for $3-4$ days. Mycelia were collected and grounded for DNA and RNA extraction. High-molecular-weight genomic DNA for singlemolecule real-time (SMRT) was extracted using the SMRTbellTM Templated Prep Kit 1.0 (PACBIO). The genomic DNA for Illumina sequencing was extracted using a CTAB method as previously described [68]. Total RNA was extracted from mycelia using the TRIZOL Kit (Invitrogen, Carlsbad, CA, USA) following the manufacture's protocol.

\section{Genome sequencing and assembly}

For PacBio Sequel genome sequencing, high molecular weight genomic DNA $(20 \mu \mathrm{g})$ was random sheared with Covaris- $\mathrm{g}$-Tube with a goal of DNA fragments of approximately $20 \mathrm{~kb}$ and end-repaired according to the manufacturer's instructions. A blunt-end ligation reaction followed by exonuclease treatment was performed to generate the SMRT Bell template, then the library was qualified and quantified using an Agilent Bioanalyzer 12 kb DNA Chip (Agilent Technologies, Santa Clara, CA, USA) and a Qubit fluorimeter (Invitrogen, Carlsbad, CA, USA). SMRT Bell cells were sequenced using the PacBio Sequel sequencing platform (Nextomics Biosciences, Co., Ltd., Wuhan, China). After adaptor removed and low quality reads filtered out, a total of $9,97 \mathrm{~Gb}$ with $8.80 \mathrm{~kb}$ average subreads were generated for $\mathrm{ZY}$ and $6.34 \mathrm{~Gb}$ with $10.68 \mathrm{~kb}$ mean subreads for GP3, respectively.

For Illumina sequencing, about $100 \mu \mathrm{g}$ of genomic DNA were sheared to $180 \mathrm{bp}$ using a Covaris LE instrument and adapted for Illumina sequencing on Illumina Hiseq Xten platform (San Diego, CA, USA) by NextOmics Biosciences. Illumina short reads were trimmed using Trimmomatic version 0.36 [69], a total of $6.42 \mathrm{~Gb}$ and $7.03 \mathrm{~Gb}$ clean data were yielded for GP3 and ZY, respectively. 
The cDNA libraries were prepared by Illumina TreSeq RNA Sample Preparation Kit (Illumina, Inc., San Diego, CA, USA) and validated according to Illumina's low-throughput protocol. The RNA-seq was conducted on an Illumina HiSeq 2500 Platform with 150 bp paired-end strategy.

A de novo genome assemblies of ZY and GP3 were generated with the PacBio Sequel reads using CANU pipeline (v1.5) [19] with default setting. The assemblies were adjusted using Arrow program, and polished using Illumina reads by Pilon [20]. Finally, the integrity of assemblies was evaluated using BUSCO [24].

\section{Repetitive elements analysis}

Repetitive elements were identified by using different methods. Transposable elements were analyzed using four programs, two programs for de novo prediction, including RepeatMoldeler (http://www.repeatmasker.org/RepeatModeler) and LTR finder [70], and the database based programs RepeatMasker (http://www.repeatmasker.org/) and Repeat-ProteinMasker (submodule in Repeatmasker) with default parameters to search Repbase [71]. Tandem Repeats Finder (TRF) was used to identify tandem repeat sequences [72]. MicroSAtellites (MISA) (https://www.plob.org/tag/misa) was used to identify simple sequence repeats (SSR) with default setting.

\section{Genome annotation}

Gene predication was performed by using a combination of ab initio-based and homology-based methods. To aid gene annotation, we generated transcript assemblies based on RNA of GP3 and ZY, respectively. For ab initio-based prediction, Augustus v2.4 [73] and Genscan (version 1.0) [74] were used to de novo predict protein coding genes with the default setting. Exonerate [75] was used to predict the gene structure with RNA-seq data. For homology-based predication, GeneWise [76] was used to predict protein coding genes by homology analysis with known protein sequences from six related species of Basidiomycota, including Galerina marginata, Gymnopus luxurians, Hydnomerulius pinast, Jaapia argillacea, Piloderma croceum, and Plicaturopsis crispa. EvidenceModler (EVM) was used to compute the weighed consensus gene structure annotation [77]. The final gene sets were obtained after removed genes with TE transposable elements by Tranposon PSI [78].

The predicted gene sets of $S$. rolfsii GP3 and ZY were functionally annotated based on similarity comparison with homologous in public databases. BLASTP was used to align the protein sequences by automated searches in NCBI-NR, Swiss-Prot (http://www expasy.org/sprot/), KEGG, GO and KOG database with E-values $\leq 1 \mathrm{e}-5$. Gene function domain annotation was conducted by InterProScan program [79]. The pathway analyses were conducted by KAAS-KEGG Automatic Annotation Serve [80].

The candidate non-coding RNA (ncRNA) was annotated by two approaches, BLAST was used to align the S. rolfsii genome against the Rfam database [81], and tRNA scan-SE [82] and RNAmmer [83] were used to predict tRNAs and rRNA, respectively.

\section{Analysis of orthologous gene families in Agariomycetes}


Orthology comparison was conducted by OrthoMCL [28] (http://va.orthomcl.org) with e-value less than le5 among protein sets of $S$. rolfsii GP3, ZY and nine related species of Agariomycetes, including Armillaria gallica (GenBank: GCA_002307695.1), Auricularia subglabra (GenBank: GCA_000265015.1), Exidia glandulosa (GenBank: GCA_001632375.1), Galerina marginata (GenBank: GCA_000697645.1), Gymnopus luxurians (GenBank: GCA_000827265.1 ), Hydnomerulius pinast (GenBank: GCA_000827185.1), Psilocybe cyanescens (GenBank: GCA_002938375.1), Scleroderma citrinum (GenBank: GCA_000827425.1), and Piloderma croceum (GenBank: GCA_000827315.1) .

\section{Phylogenetic analysis and synteny analysis}

The phylogenetic tree of $S$. rolfsii GP3, ZY and the above related nine species of Agaricomycetes was constructed by single copy gene based on the orthologous gene families analysis. Mafft [84] software was conducted to align the protein sequence of the single copy gene, and converted to coding sequence alignment. Gblocks [85] was used to extract the well-aligned regions of each coding sequence alignments. RAxML 8.2.12 [86] was carried out to generate the maximum-likelihood tree with 100 bootstrap replicates with Psilocybe cyanescens as an outgroup. The whole genome aligner Murmer 3.06 [87] was used for comparative analysis of the assemblies of GP3 and ZY. Dot plots between contigs of GP3 and ZY were created by MuMerplot programs from the MuMmer package.

\section{Identification of the pathogenicity related genes}

The S. rolfsii GP3 and ZY protein sets were used to conduct a BLASTP search against PHI base (a database of Host-Pathogen gene interaction) with e-value less than $1 \mathrm{e}-5$ to identify pathogenicity genes. Putative carbohydrate active enzymes (CAZymes) of S.roflsii GP3 and ZY were annotation using dbCAN (dbCAN HMMs 5.0) [88] servers, with an e-value of less than $1 \mathrm{e}-5$ and more than $70 \%$ coverage. The CAZymes were classified as per type of reaction catalyzed like Glycoside Hydrolases (GHs), Polysaccharide Lyases (PLs), Carbohydrate Esterases (CEs), Glycosyl Transferase (GTs), CarbohydrateBinding Modules (CBMs), and

Auxillary Activities (AAs) as described in CAZyme database classification (http://www.cazy.org) [89].

\section{Secretome and effector predication}

The prediction of the S. rolfsii strains GP3 and ZY secretome was conducted based on the following pipeline. SignalP version 4.0 [90] was used to analyze signal peptide and cleavage sites of S. rolfsii GP3 and ZY proteins. Candidate proteins with signal peptide were identified by Protcomp 9.0 (http://www.softberry.com/berry.phtml) using the LocDB and PotLoc DB databases and proteins predicted as extracellular or unknown were kept for next analysis. The candidate proteins were conducted by TMHMM version 2.0 [91] to identify protein with transmembrane domains, and all proteins with $0 \mathrm{TM}$ or $1 \mathrm{TM}$, if located in the predicted $\mathrm{N}$ - terminal signal peptide, were kept. The candidate proteins that harbored a putative glycophosphatidylinositol membrane-anchoring domain were identified by GPIsom (http://gpi.unibe.ch/) [92]. The remaining proteins without GPI-anchor were predicted with Target P [93], 
the proteins with a Target $\mathrm{P}$ Loc $=\mathrm{S}$ or - were kept in the final secretome databases. The candidate secretory proteins were blasted in NR database and PHI database to annotate the protein function and also searched against CAZyme database for function of CAZymes. The candidate effectors were identified by passing the secretome through the program Effector $P 1.0$ [94]. Putative effector candidates were manually inspected and those with known plant cell wall degrading catalytic domains, such as lipase, peptidase, CAZymes and cutinase were filter out. Putative candidate effectors were also screened for those candidates with molecular weight ranged from 50 to 300 amino acids, and at least 4 cysteine amino acids in their sequences.

\section{Supplementary Information}

Additional file 1: Figure S1. Statistics of BUSCO assessment of S. rolfsii GP3 and ZY genome assemblies. a Total searched BUSCOs of S. rolfsii GP3 and ZY; b Distribution of different BUSCOs in GP3 and ZY. S, Complete and single-copy BUSCOs; D, Complete and duplicated BUSCOs; F, Fragmented BUSCOs; M, Missing BUSCOs.

Additional file 2: Figure S2. Genome annotation statistics of S. rolfsii GP3 and ZY by blasting against five databases.

Additional file 3: Figure S3. KOG distribution of predicted proteins from S.roflsii GP3 and ZY.

Additional file 4: Figure S4. Go annotation enrichment analysis of genes of S. rolfsii GP3 and ZY. a Number of genes in biological process, cellular component, and molecular function of S. rolfsii GP3 and $Z Y ; \mathbf{b}$ Percent of genes involved in molecular function, biological process, and cellular component of $S$. rolfsii GP3; c Percentage of genes involved in molecular function, biological process, and cellular component of $S$. rolfsii ZY.

Additional file 5: Figure S5. KEGG classification of genes of S. rolfsii GP3 and ZY. a Distribution of genes among processes, metabolism, and organismal systems of S. rolfsii GP3;

b Distribution of genes among processes, metabolism, and organismal systems of S. rolfsii ZY.

Additional file 6: Figure S6. Analysis of orthologs of two S. rolfsii strains and other species in Agaricomycetes.

Additional file 7: Figure S7. The pipeline for putative secretomes and effectors analysis of S. roflsii GP3 and ZY.

Additional file 8. Table S1. List of ncRNAs in genomes of S. rolfsii GP3 and ZY.

Additional file 9. Table S2. Comparison of gene families of GP3, ZY, and other species in Agaricomycetes.

Additional file 10. Table S3. Identification of repetitive elements of S. rolfsii GP3 and ZY by five programs. 
Additional file 11. Table S4. Repetitive elements in the genomes of S. rolfsii strains.

Comparison of percentage of repetitive elements of each categories in the genomes of S. rolfsii GP3, ZY, and MR10.

Additional file 12. Table S5. Unique Pathogen Host Interaction (PHI) genes in the genome of S. rolfsii GP3 and ZY.

Additional file 13. Table S6. Comparison of CAZymes involved in cellulose degradation in the genomes of plant pathogens.

The values reflect the total numbers in each family of CAZymes

Additional file 14. Table S7. Comparison of CAZymes involved in hemicellulose degradation in the gnomes of plant pathogens.

The values reflect the total numbers in each family of CAZymes

Additional file 15. Table S8. Comparison of CAZymes involved in pectin degradation in the genomes of plant pathogens.

The values reflect the total numbers in each family of CAZymes

Additional file 16. Table S9. List of secreted CAZymes in the genome of S. rolfsii GP3 and ZY.

\section{Abbreviations}

AA: Auxiliary activity; A. subglabra: Auricularia subglabra; B. cinerea: Botrytis cinerea; CAZyme: Carbohydrate-active Enzyme; CBM: Carbohydrate-binding module; CE: Carbohydrate esterase; endo-PG: endo-polygalacturonase; E. glandulosa: Exidia glandulosa; GH: Glycoside hydrolase; G. Iuxurians: Gymnopus luxurians; GPI: Glycosylphosphatidylinositl anchor; GT: Glycosyltransferase; P. croceum: Piloderma croceum; P. cyanescens: Psilocybe cyanescensp; P. tinctorius. Pisolithus tinctorius. PL: Polysaccharide lyase; PHI: Pathogen- host interaction; P. graminis: Puccinia graminis; $R$. solani: Rhizotonia solani; S. rolfsir: Sclerotium rolfsii; S. slceorotiorum: Sclerotinia sclerotiorum; U. maydis: Ustilago maydis, V. dahliae: Verticillium dahlia.

\section{Declarations}

\section{Ethics approval and consent to participate}

Not applicable.

\section{Consent for publication}


Not applicable

\section{Availability of data and materials}

The genomes of S. rolfsii strains GP3 and ZY were deposited in GenBank under BioProject numbers:

PRJNA635225, PRJNA635226, and BioSample numbers: SAMN15029893, SAMN15029894, respectively.

\section{Competing interests}

The authors declare that they have no competing interests.

\section{Funding}

This work was supported by grants from the National Natural Science Foundation of China (31971981), National Key R\&D Program of China (2018YFD0201000) and the China Agricultural Research System (CARS-13).

\section{Authors' contributions}

The research was designed and wrote by LY, bioinformatics analysis was performed by $\mathrm{ZH}$, the experiments were performed by WD, PM, LY, and YP, manuscript was critically revised by $Y L, D X, Y N, X W$, $\mathrm{HS}$, and BS. All authors read and approved the final manuscript.

\section{Acknowledgments}

Not applicable.

\section{References}

1. Nalim FA, Starr JL, Woodard KE, Segner S, Keller NP. Mycelial compatibility groups in Texas peanut field populations of Sclerotium rolfsii. Phytopathology. 1995;85:1507-15

2. Harlton CE, Uvesque CA, Punja ZK. Genetic diversity in Sclerotium (Athelia) rolfsii and related species. Phytopathology, 1995;85:1269-12

3. Cilliers A, Herselman L, Pretorius Z. Genetic variability within and among mycelia compatibility groups of Sclerotium rolfsii in South Africa. Phytopathology. 2000;90: 1026-1031.

4. Punja ZK. The biology, ecology, and control of Sclerotium rolfsii. Ann Rev Phytopathol. 1985;23:97127.

5. Backman PA, Brenneman TB. Peanut stem rot. In: Kakalis-Burelle, Proter DM, Rodriguez-kabana R, Smith DH, Subrahmanyam P. editors. Compendium of Peanut Diseases. Second Edition. MN, Amercan Phytopathological Society; 1997. P 97:36-37.

6. Kemerait R. Georgia plant disease loss e In: Woodward JWW. editor. CAES Publications UGA Cooperative Extension. 2011;P 102-4:13. 
7. Mayee CD, Datur VV. Diseases of groundnut in the tropics. Rev Tropic Plant Pathol. 1998;5: 85-118.

8. Chen KR, Ren L, Xu L, Chen W, Liu F, Fang XP. Research progress on peanut southern stem rot caused by Sclerotium rolfsii. Chin J Oil Crop Sci. 2018;40(2): 302-308.

9. Branch WD, Brenneman TB. Stem rot disease evaluation of mass-selected peanut populations. Crop Prot. 1999;18:127-1

10. Branch WD, Brenneman TB. Field evaluation for the combination of white mold and tomato spotted wilt disease resistance among peanut genotypes. Crop Prot. 2009; 28:595-598.

11. Woodward JE, Brenneman TB, Kemerait RC, Smith NB, Culbreath AK, Stevenson KL. Use of resistant cultivars and reduced fungicide programs to manage peanut diseases in irrigated and non-irrigated fields. Plant Dis. 2008;92:896-902.

12. Yan LY, Song WD, Lei Y, Wan LY, Huai DX, Kang YP, Chen YN, Liao BS. Evaluation of peanut accessions for resistance to Sclerotium stem rot. Chin J Oil Crop Sci. 2019; 41(5):1-7.

13. Li JT, Fan HF, Wang JM, Liu F. Toxicity and field control efficacy of four fungicides against Sclerotium rolfsii. Chin J Oil Crop Sci; 2013;35(6): 686-691.

14. Remesal E, Jordan-Ramirez R, Jimenez-Diaz RM, Navas-Cortes JA. Mycelial compatibility groups and pathogenic diversity in Sclerotium rolfsii populations from sugar beet crops in Mediterranean-type climate regions. Plant Pathol. 2012;61:739-753.

15. Chandra Sekhar Y, Khayum Ahammed S, Prasad TNVKV, Sarada Jayalakshmi Devi R. Morphological and pathogenic variability of Sclerotium rolfsii isolates causing stem rot in groundnut. Int J Pure App Biosci. 2017;5 (5): 478-487.

16. Punja ZK, Huang JS, Jenkins S F. Relationship of mycelial growth and production of oxalic acid and cell wall degrading enzymes to virulence in Sclerotium rolfsii. Can J Plant Pathol. 1985;7(2):109-216.

17. Jebaraj MD, Aiyanathan KEA, Nakkeeran S. Virulence and genetic diversity of Sclerotium rolfsii infecting groundnut using nuclear (RAPD \& ISSR) markers. J Environ Biol. 2017;38:147-159.

18. Cooper WE. Strains of, resistance to, and antagonists of Sclerotium rolfsii. Phytopathology. 1961;51: 113-116.

19. Koren S, Walenz BP, Berlin K, Miller JR, Bergman NH, Phillippy AM. Canu: scalable and accurate longread assembly via adaptive $k$-mer weighting and repeat separation. Genome Res. 2017;27(5): 722736.

20. Walker BJ, Abeel T, Shea T, Priest M, Abouelliel A, Sakthikumar S, Cuomo CA, Zeang QD, Qortman J, Young SK, et al. Pilon: An integratool for comprehensive microbial variant detection and genome assembly i PLoS One. 2014;9: e112963.

21. Zheng A, Lin R, Zhang D, Qin P, Xu L, Ai P, Ding L, Wang Y, Chen Y, Liu Y, et al. The evolution and pathogenic mechanisms of the rice sheath blight pathogen. Nat Commun. 2013;4:1424.

22. Kamper J, Kahmann R, Bolker M, Ma LJ, Brefort T, Saville BJ, Banuett F, Kronstad JW, Gold SE, Muller 0 , et al. Insights from the genome of the biotrophic fungal plant pathogen Ustilago maydis. Nature. 2006;4444(7115):97-101. 
23. Duplessis S, Cuomo CA, Lin YC, Aerts A, Tisserant E, Veneault-Fourrey C, Joly DL, Hacquard S, Amselem J, Cantarel $\mathrm{BL}$, et al. Obligate biotrophy features unraveled by the genomic analysis of rust fungi. Proc Natl Acad Sci USA. 2011;108(22):9166-9171.

24. Simão FA, Waterhouse RM, loannidis P, Kriventseva EV, Zdobnov EM. BUSCO: assessing genome assembly and annotation completeness with single-copy orthologs. Bioinformatics. 2015;31: 32103212.

25. Meinhardt LW, Costa GG, Thomazella DP, Teixeira PJPL, Carazzolle MF, Schuster SC, Carlson JE, Guiltinan MJ, Mieczkowski P, Farmer A, et al. Genome and secretome analysis of the hemibiotrophic fungal pathogen, Moniliophthora roreri, which causes frosty pod rot disease of cacao: mechanisms of the biotrophic and necrotrophic phases. BMC Genomics. 2014;15:164.

26. Kohler A, Kuo A, Nagy LG, Morin E, Barry KW, Buscot F, Canbäck B, Choi C, Cichocki N, Clum A, et al. Convergent losses of decay mechanisms and rapid turnover of symbiosis genes in mycorrhizal mutualists. Nat Genet. 2015;47(4):410-41

27. Iquebal MA, Rukam S, Parakhia TMV, Deepak S, Sarika J, Rathod VM, Padhiyar SM, Kumar N, Rai A, Kumar D. Draft whole genome sequence of groundnut stem rot fungus Athelia rolfsii revealing genetic architect of its pathogenicity and virulence. Sci Rep. 2017; 7:5299.

28. Li L, Stoeckert CJJr, Roos DS. OrthoMCL: identification of ortholog groups for eukaryotic genomes. Genome Res. 2003;13: 2178-

29. Floiudas D, Binder M, Riley R, Barry K, Blanchette RA, Henrissat B, Martinez AT, Otillar T, Spatafora JW, Yadav JS, et al. The paleozoic origin of enzymatic lignin decomposition reconstructed from 31 fungal genomes. Science. 2012;336(6089):1715-1719.

30. Nagy LG, Riley R, Tritt A, Adam C, Daum C, Daum C, Flouda D, Sun H, Yadav JS, Tanilinan J, et al. Comparative genomics of early- diverging mushroom-forming fungi provides insights into the origins of lignocellulose decay capabilities. Mol Biol Evol. 2016;33(4):959-970.

31. Cantarel BL, Coutinho PM, Rancurel C, Bernard T, Lombard V, Henrissat B. The Carbohydrate-Active EnZymes database (CAZy): an expert resource for Glycogenomics. Nucleic Acids Res. 2009; 37:233238.

32. Sprockett DD, Piontkivska H, Blackwood CB. Evolutionary analysis of glycosyl hydrolase family 28 (GH28) suggests lineage- specific expansions in necrotrophic fungal pathogens. Gene, 2011;479:2936.

33. van der Does HC, Rep M. Virulence genes and the evolution of host specificity in plant-pathogenic fungi. Mol Plant Microbe Interact. 2007;20(10):1175-11

34. Petre B, Kamoun S. How do filamentous pathogens deliver effector proteins into plant cells? PLoS Biol. 2014;12(2):e1001801.

35. Mueller O, Kahmann R, Aguilar G, Trejo-Aguilar B, Wu A, de Vries RP. The secretome of the maize pathogen Ustilago maydis. Fungal Genet Biol. 2008;45suppl 1: 63-70. 
36. Cantu D, Segovia V, MacLean D, Bayles R, Chen XM, Kamoun S, Dubcovsky J, Saunders DGO, Uauy C. Genome analyses of the wheat yellow (stripe) rust pathogen Puccinia Striiformis Sp. Tritici reveal polymorphic and haustorial expressed secreted proteins as candidate effectors. BMC Genomics. 2013;14:270.

37. Oliver RP, Solomon PS. New developments in pathogenicity and virulence of necrotrophs. Curr Opin Plant Biol. 2010; 13:415-

38. Bateman DF and Beer SV. Simultaneous production and synergistic action of oxalic acid and polygalacturonase during pathogenicity by Sclerotium rolfsii. Phytopath. 1965;55:204-211.

39. Bateman DF. The polygalacturonase complex produced by Sclerotium rolfsii. Physiol Plant Pathol. 1972;2:175-1

40. Bateman DF. Some characteristics of the cellulase system produced by Sclerotium rolfsii Phytopathology. 1969;59:37-42.

41. Xie CZ, Huang $\mathrm{CH}$, Vallad GE. Mycelial compatibility and pathogenic diversity among Sclerotium rolfsii isolates in the Southern United States. Plant Dis. 2014; 98:1685-1694.

42. Saraswathi M, Jaya MR. Variation in oxalic acid production by groundnut isolates of Sclerotium rolfsii. Biores Bull. 2014;3(2):1-3.

43. Amselem J, Cuomo CA, van Kan JAL, Viaud M, Benito EP, Couloux A, Coutinho PM, de Vries RP, Dyer PS, Fillinger S, et al. Genomic analysis of the necrotophic fungal pathogens Scerotinia sclerotiorum and Botrytis cinerea. PLoS Genetics. 2011;7(8):e1002230.

44. Chiapello H, Mallet L, Guerin C, Aguileta G, Amselem J, Kroj T, Ortega-Abboud E, Lebrun MH, Henrissat $B$, Gendrault A, et al. Deciphering genome content and evolutionary relationships of isolates from the fungus Magnaporthe oryzae attacking different host plants. Genome Biol Evol. 2015;7(10):2896-2

45. Kubicek CP, Starr TL, Glass NL. Plant cell wall-degrading enzymes and their secretion in plantpathogenic fungi. Annu Rev Phytopathol. 2014;52(1):427-4

46. Guo M, ChenY, DuY, DongY, Guo W, Zhai S, Dong SM, Zhang ZG, Wang YC, Wang P, Zheng XB. The bZIP transcription factor MoAP1 mediates the oxidative stress response and is critical for pathogenicity of the rice blast fungus Magnaporthe oryzae. PLoS Pathog. 2011;7:e1001302.

47. Malinovsky FG, Batoux M, Schwessinger B,Youn JH, Stransfeld L, Win J, Kim SK, Zipfel C. Antagonistic regulation of growth and immunity by the Arabidopsis basic helix-loop-helix transcription factor homolog of brassinosteroid enhanced expression interacting with increased leaf inclination binding bHLH1. Plant 2014;164:1443-1455.

48. Yang Y, Liu XB, Cai JM, Chen YP, Li BX, Guo ZK, Huang GX. Genomic characteristics and comparative genomics analysis of the endophytic fungus Sarocladium brachiariae. BMC Genomics. 2019;20:782.

49. Cook D, Mesarich $\mathrm{CH}$, Thomma BPHJ. Understanding plant immunity as a surveillance system to detect invasion. Annu Rev Phytopathol. 2015;53:541-563.

50. Jones JDG, Dangl JL. The plant immune system. Nature. 2006; 444:323-329. 
51. Rovenich H, Boshoven JC, Thomma BPHJ. Filamentous pathogen effector functions: of pathogens, hosts and microbiomes. Curr Opin Plant Biol. 2014;20: 96-103.

52. Friesen TL, Faris JD, Solomon PS, Oliver RP. Host-specific toxins: effectors of necrotrophic pathogenicity. Cell Microbiol. 2008;10:1421-1428.

53. Lu S, Gillian Turgeon B, Edwards MC. A ToxA-like protein from Cochliobolus heterostrophus induces light-dependent leaf necrosis and acts as a virulence factor with host selectivity on maize. Fungal Genet Biol. 2015;81:12-24.

54. Whigham E, Qi S, Mistry D, Surana P. Xu R, Fuerst G, Pliego C, Biindschedler LV, Spanu PD, Dickerson JA, et al. Broadly conserved fungal effector BEC1019 suppresses host cell death and enhances pathogen virulence in powdery mildew of barley (Hordeum vulgare). Mol Plant Microbe Interact. 2015;28:968-983.

55. Lyu X, Shen C, Fu Y, Xie J, Jiang D, Li G, Cheng J. A small secreted virulence-related protein is essential for the necrotrophic interactions of Sclerotinia sclerotiorum with its host plants. PLoS Pathog. 2016;12:e1005435.

56. Liang Y, YajimaW, Davis MR, Kav NNV, Strelkov SE. Disruption of a gene encoding a hypothetical secreted protein from Sclerotinia sclerotiorum reduces its virulence on canola (Brassica napus). Can J Plant Pathol. 2013;35:46-55.

57. Lyu X, Shen C, Fu Y, Xie J, Jiang D, Li G, Cheng J. Comparative genomic and transcriptional analyses of the carbohydrate-active enzymes and secretomes of phytopathogenic fungi reveal their significant roles during infection and development. Sci Rep. 2015;5.

58. Kombrink A, Sanchez-Vallet A, Thomma BPHJ. The role of chitin detection in plant-pathogen interactions. Microbes Infect. 2011;13:1168-

59. Klosterman SJ, Subbarao KV, Kang S, Veronese P, Gold SE, Thomma BPHJ, Chen ZH, Henrissat B, Lee $\mathrm{YH}$, Park JS, et al. Comparative genomics yields insights into niche adaptation of plant vascular wilt p PLoS Pathog. 2011;7(7):e1002137.

60. Zhang Z, Fradin EF, de Jonge R, van Esse HP, Smit P, Liu CM, Thomma BPHJ. Optimized agroinfiltration and virus-induced gene silencing to study Ve1-mediated Verticillium resistance in tobacco. Mol Plant Microbe Interact. 2013;26:182-

61. van Kan JA. Licensed to kill: the lifestyle of a necrotrophic plant pathogen. Trends Plant Sci. 2006;11(5):247-253.

62. Kombrink A, Thomma BPHJ. LysM effectors: secreted proteins supporting fungal life. PLoS Pathog. 2013; 9:e1003769.

63. Rouxel T, Grandaubert J, Hane JK, Hoede C, van de Wouw AP, Couloux A, Dominguez V, Anthouard V, Bally P, Bourras S, et al. Effector diversification within compartments of the Leptosphaeria maculans genome affected by Repeat-Induced Point mutations. Nat Commun. 2011;2:202.

64. Derbyshire M, Denton-Giles M, Hegedus D, Seifbarghi S, Rollins J, van Kan J, Seidl MF, Faino L, Mbengue $\mathrm{M}$, Navaud $\mathrm{O}$, et al. The complete genome sequence of the phytopathogenic fungus 
Sclerotinia s/cerotiorum reveals insights into the genome architecture of broad host range pathogens. Genome Biol Evol. 2017;9(3):593-618.

65. Song WD, Yan LY, Lei Y, Wan LY, Huai DX, Kang YP, Ren XP, Jiang HF, Liao BS. Analysis of genetic variation among Sclerotium rolfsii isolates from China based on mycelial compatibility groups, ITS sequence and biological characteristics. Acta Phytopathol Sinica. 2018;48(3):305-312.

66. Kritzman G, I Chet, Y. Kenis. The role of oxalic acid in the pathogenic behavior of Sclerotium rolfsii Expt Mycol. 1977;1:280-285.

67. Shokes FM, Weber Z, Gorbet DW, Pudelko HA, Taczanowski M凶Evaluation of peanut genotypes for resistance to southern stem rot using an agar disk technique. Peanut Sci.1998;25:12-17.

68. Wu ZH, Wang TH, Huang W, Qu YB. A simplified method for chromosome DNA preparation from filamentous Fungi. Mycosystema.2001;20:575-

69. Bolger AM, Lohse M, Usadel B. Trimmomatic: a flexible trimmer for Illumina sequence data. Bioinformatics. 2014;3 (15):2114-

70. Zhao X, Wang H. LTR_FINDER: an efficient tool for the prediction of full-length LTR retrotransposons. Nucleic Acids Res. 2007;35:265-268.

71. Jurka J, Kapitonov VV, Pavlicek A, Klonowski P, Kohany O, Walichiewicz J. Repbase Update, a database of eukaryotic repetitive elements. Cytogenet genome Res. 2005;110(14):462-

72. Benson G. Tandem repeats finder: a program to analyze DNA sequences. Nucleic Acids $R$ 1999;27(2):573.

73. Stanke M, Morgenstern B. AUGUSTUS: a web server for gene prediction in eukaryotes that allows user-defined constraints. Nucleic Acids Res. 2005;33:465-

74. Burge C, Karlin S. Prediction of complete gene structures in human genomic DNA. J Mol Bio. 1997;268:78-94.

75. Slater GS, Birney E. Automated generation of heuristics for biological sequence comparison. BMC Bioinformatics. 2005;6:31.

76. Birney E, Durbin R. Using GeneWise in the Drosophila annotation e Genome Res. 2000;10: 547.

77. Haas BJ, Salzberg SL, Zhu W, Pertea M, Allen JE, Orvis J, Whte O, Buell CR, Wortman JR. Automated eukaryotic gene structure annotation using EVidenceModeler and the program to assemble spliced a Genome Biol. 2008;9:R7.

78. Yagi M, Kosugi S, Hirakawa H, Ohimiya A, Tanase K, Harada T, Kishimoto K, Nakayama M, Ichimura $\mathrm{K}$, Onozaki T, et al. Sequence analysis of the genome of carnation (Dianthus caryophyllus). DNA Res. 2014;21:231-241.

79. Jones P, Binns D, Chang HY, Fraser M, Li WZ, McAnulla C, McWilliam H, Maslen J, Mitchell A, Nuka G, et al. InterProScan 5: genome-scale protein function classification. Bioinformatics. 2014;30:12361240.

80. Moriya Y, Itoh M, Okuda S, Yoshizawa AC, Kanehisa M. KAAS: an automatic genome annotation and pathway reconstruction server. Nucleic Acids Res. 2007; 35Suppl 2:182-18 
81. Griffiths-Jones S, Moxon S, Marshall M, Khanna A, Eddy SR, Bateman A. Rfam: annotating noncoding RNAs in complete genomes. Nucleic Acids Res. 2005;33:121.

82. Lowe TM, Eddy SR. tRNAscan-SE: a program for improved detection of transfer RNA genes in genomic sequence. Nucleic Acids Res. 1997;25: 955-9

83. Lagesen $K$, Hallin P, Rodland EA, Starfeldt HH, Rognes T, Ussery DW. RNAmmer: consistent and rapid annotation of ribosomal RNA genes. Nucleic Acids Res. 2007;35: 3100.

84. Katoh K, Standley DM. MAFFT multiple sequence alignment software version 7: improvements in performance and u Mol Biol Evol. 2013;30:772-780.

85. Talavera G, Castresana J. Improvement of phylogenies after removing divergent and ambiguously aligned blocks from protein sequence alignments. Systematic Biol. 2007;56:564-

86. Stamatakis A. RAxML version 8: a tool for phylogenetic analysis and post-analysis of large phylogenies. Bioinformatics. 2014;30:1312-

87. Kurtz S, Phillippy A, Delcher AL, Smoot M, Shumway M, Antonescu C, Salzberg SL. Versatile and open software for comparing large genomes. Genome Biol. 2014;5:12.

88. Yin YB, Mao XZ, Yang JC, Chen X, Mao FL, Xu Y. dbCAN: a web resource for automated carbohydrateactive enzyme annotation. Nucleic Acid Res. 2012;40:445-451.

89. Lombard V, Golaconda Ramulu H, Drula E, Coutinho PM, Henrissat B. The Carbohydrate-active enzymes database (CAZy) in 2013. Nucleic Acids Res. 2014;42:490-

90. Petersen TN, Brunak S, von Heijne G, Nielsen H. SignalP 4.0: discriminating signal peptides from transmembrane regions. Nat Methods. 2011;8:785-786.

91. Krogh A, Larsson B, von Heijne G, Sonnhammer ELL. Predicting transmembrane protein topology with a hidden Markov model: Application to complete genomes. J Mol Biol. 2001;305:567-580.

92. Fankhauser N, Maser P. Identification of GPI anchor attachment signals by a Kohonen selforganizing map. Bioinformatics. 2005;21:1846-18

93. Bendtsen JD, Nielsen H, Widdick D, Palmer T, Brunak S. Prediction of twin-arginine signal peptides. BMC B 2005;6: 167.

94. Sperschneider J, Gardiner D M, Dodds PN, Tini F, Covarelli L, Singh KB, MannersJM, Taylor JM. EffectorP: predicting fungal effector proteins from secretomes using machine learning. New Phytol. 2015;210(2):743-7

\section{Tables}

Table 1 Genome characteristic and assemblies feature of $S$. rolfsii strains. 


\begin{tabular}{cccc}
\hline \multirow{2}{*}{ Assembly Feature } & \multicolumn{3}{c}{ Sclerotium rolfsii } \\
\cline { 2 - 4 } & GP3 & ZY & MR10 \\
\hline Number of contigs & 27 & 23 & 8,919 \\
The longest contig (Mb) & 5.79 & 5.67 & N/A \\
Genome size (Mb) & 70.51 & 70.61 & 73.18 \\
N90 (Mb) & 2.71 & 2.55 & N/A \\
N50 (Mb) & 3.67 & 3.71 & 0.032 \\
GC content (\%) & 46.27 & 46.29 & 46.16 \\
Repetitive sequence of assembly (\%) & 14.75 & 14.66 & 3.73 \\
Number of Predicted genes & 17,097 & 16,743 & 16,830 \\
Average gene length (bp) & 2013.91 & 2039.76 & N/A \\
Average coding sequence length (bp) & 1578.56 & 1599.28 & N/A \\
Average number of exons per gene & 6.85 & 6.75 & N/A \\
\hline
\end{tabular}

Table 2 Putative effectors of $S$. rolfsii GP3 and ZY. 


\begin{tabular}{|c|c|c|c|}
\hline \multicolumn{4}{|r|}{ Putative effector in GP3 } \\
\hline Eeffctor name & Protein length (a. a) & \# of Cys & NR annotation \\
\hline evm.model.Contig2.1283 & 231 & 5 & unknown \\
\hline evm.model.Contig2.1284 & 226 & 14 & AtMMH-1 [Pycnoporus coccineus BRFM310] \\
\hline evm.model.Contig2.36 & 129 & 17 & hypothetical protein PLICRDRAFT_173401 [Plicaturopsis crispa FD-325 SS-3] \\
\hline evm.model.Contig2.37 & 124 & 8 & hypothetical protein PLICRDRAFT_156776 [Plicaturopsis crispa FD-325 SS-3] \\
\hline evm.model.Contig3.1383 & 121 & 10 & Diphthamide synthesis [Daedalea quercina L-15889] \\
\hline evm.model.Contig4.1113 & 193 & 5 & unknown \\
\hline evm.model.Contig9.127 & 231 & 14 & hypothetical protein CY34DRAFT_799688 [Suillus luteus UH-Slu-Lm8-n1] \\
\hline evm.model.Contig9.369 & 123 & 7 & hypothetical protein PLICRDRAFT_50833 [Plicaturopsis crispa FD-325 SS-3] \\
\hline evm.model.Contig13.592 & 121 & 4 & putative 4-coumarate--CoA ligase 1 [Hypsizygus marmoreus] \\
\hline evm.model.Contig14.108 & 121 & 4 & unknown \\
\hline evm.model.Contig14.22 & 156 & 12 & hypothetical protein PLEOSDRAFT_1036789 [Pleurotus ostreatus PC15] \\
\hline evm.model.Contig2.1062 & 136 & 8 & hypothetical protein PLICRDRAFT_49174 [Plicaturopsis crispa FD-325 SS-3] \\
\hline evm.model.Contig2.277 & 123 & 8 & hypothetical protein PLEOSDRAFT_1113736 [Pleurotus ostreatus PC15] \\
\hline evm.model.Contig3.1079 & 198 & 5 & hypothetical protein TRAVEDRAFT_31233 [Trametes versicolor FP-101664 SS1] \\
\hline evm.model.Contig4.134 & 121 & 4 & predicted protein [Fibroporia radiculosa] \\
\hline evm.model.Contig7.302 & 278 & 14 & hypothetical protein CONPUDRAFT_162258 [Coniophora puteana RWD-64-598 SS2] \\
\hline evm.model.Contig10.404 & 202 & 15 & hypothetical protein GYMLUDRAFT_41536 [Gymnopus luxurians FD-317 M1] \\
\hline evm.model.Contig11.391 & 202 & 15 & hypothetical protein CONPUDRAFT_180601 [Coniophora puteana RWD-64-598 SS2] \\
\hline evm.model.Contig13.385 & 196 & 4 & hypothetical protein PLICRDRAFT_26010 [Plicaturopsis crispa FD-325 SS-3] \\
\hline \multicolumn{4}{|r|}{ Putative effector in $\mathrm{ZY}$} \\
\hline Eeffctor Name & Protein length (a. a) & \# of Cys & NR annotation \\
\hline evm.model.Contig8.598 & 198 & 5 & hypothetical protein JAAARDRAFT_36197 [Jaapia argillacea MUCL 33604] \\
\hline evm.model.Contig8.235 & 107 & 4 & predicted protein [Laccaria bicolor S238N-H82] \\
\hline evm.model.Contig1.1391 & 78 & 4 & hypothetical protein PLICRDRAFT_129037 [Plicaturopsis crispa FD-325 SS-3] \\
\hline evm.model.Contig1.885 & 123 & 8 & hypothetical protein PLICRDRAFT_98558 [Plicaturopsis crispa FD-325 SS-3] \\
\hline evm.model.Contig2.1000 & 122 & 8 & tripeptidyl peptidase A [Schizopora paradoxa] \\
\hline evm.model.Contig2.1371 & 127 & 8 & hypothetical protein PLICRDRAFT_52549 [Plicaturopsis crispa FD-325 SS-3] \\
\hline evm.model.Contig3.314 & 136 & 8 & hypothetical protein PHLGIDRAFT_252913 [Phlebiopsis gigantea 11061_1 CR5-6] \\
\hline evm.model.Contig8.100 & 168 & 13 & hypothetical protein CY34DRAFT_389888 [Suillus luteus UH-Slu-Lm8-n1] \\
\hline evm.model.Contig9.732 & 121 & 4 & hypothetical protein GYMLUDRAFT_76493 [Gymnopus luxurians FD-317 M1] \\
\hline evm.model.Contig10.42 & 272 & 14 & endopolygalacturonase 2 precursor [Athelia rolfsii] \\
\hline evm.model.Contig11.292 & 98 & 4 & hypothetical protein STEHIDRAFT_145500 [Stereum hirsutum FP-91666 SS1] \\
\hline evm.model.Contig12.146 & 202 & 15 & hypothetical protein PILCRDRAFT_817845 [Piloderma croceum F 1598] \\
\hline evm.model.Contig15.491 & 193 & 11 & hypothetical protein CERSUDRAFT_118386 [Gelatoporia subvermispora B] \\
\hline evm.model.Contig17.14 & 121 & 4 & alpha/beta-hydrolase [Neolentinus lepideus HHB14362 ss-1] \\
\hline evm.model.Contig1.860 & 124 & 8 & predicted protein [Fibroporia radiculosa] \\
\hline evm.model.Contig1.861 & 129 & 8 & predicted protein [Fibroporia radiculosa] \\
\hline evm.model.Contig2.662 & 124 & 8 & predicted protein [Fibroporia radiculosa] \\
\hline evm.model.Contig3.613 & 58 & 6 & Protein priA [Grifola frondosa] \\
\hline evm.model.Contig4.1281 & 58 & 6 & hypothetical protein SISSUDRAFT_985847 [Sistotremastrum suecicum HHB10207 ss-3] \\
\hline evm.model.Contig8.582 & 226 & 14 & pectin lyase-like protein [Schizopora paradoxa] \\
\hline
\end{tabular}

\section{Figures}


A

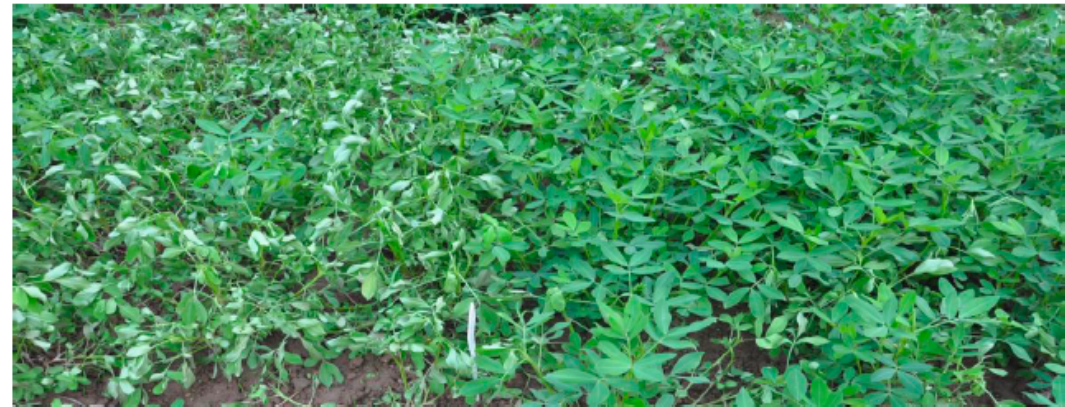

ZY

C

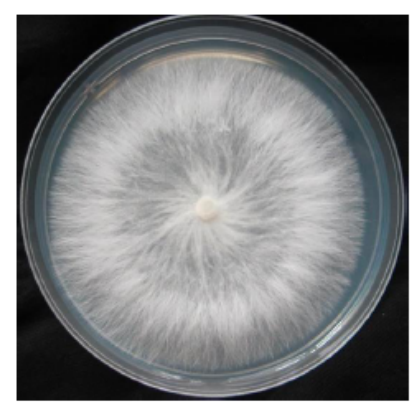

ZY

E

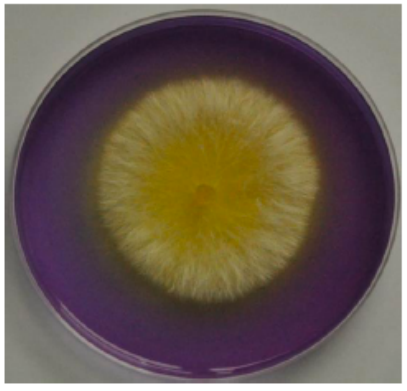

ZY

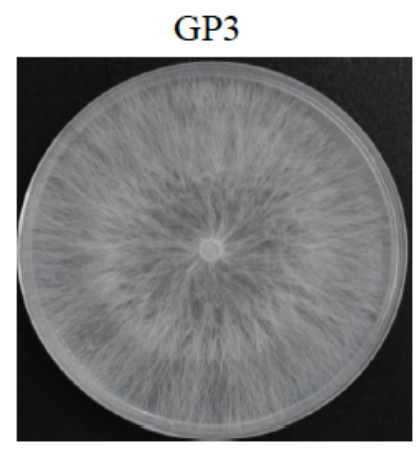

GP3

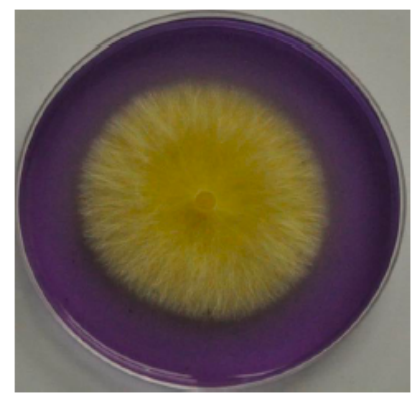

GP3
B

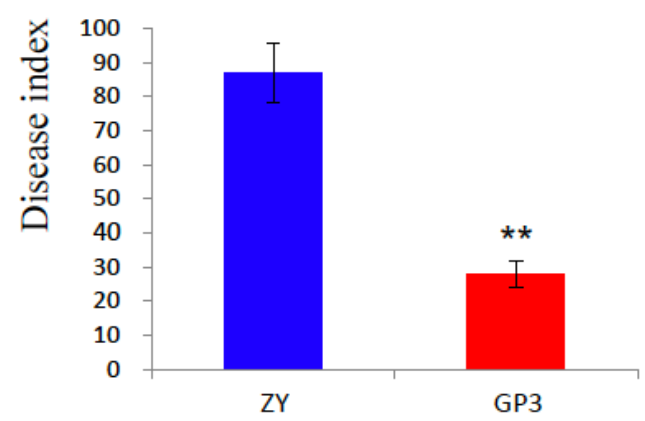

D
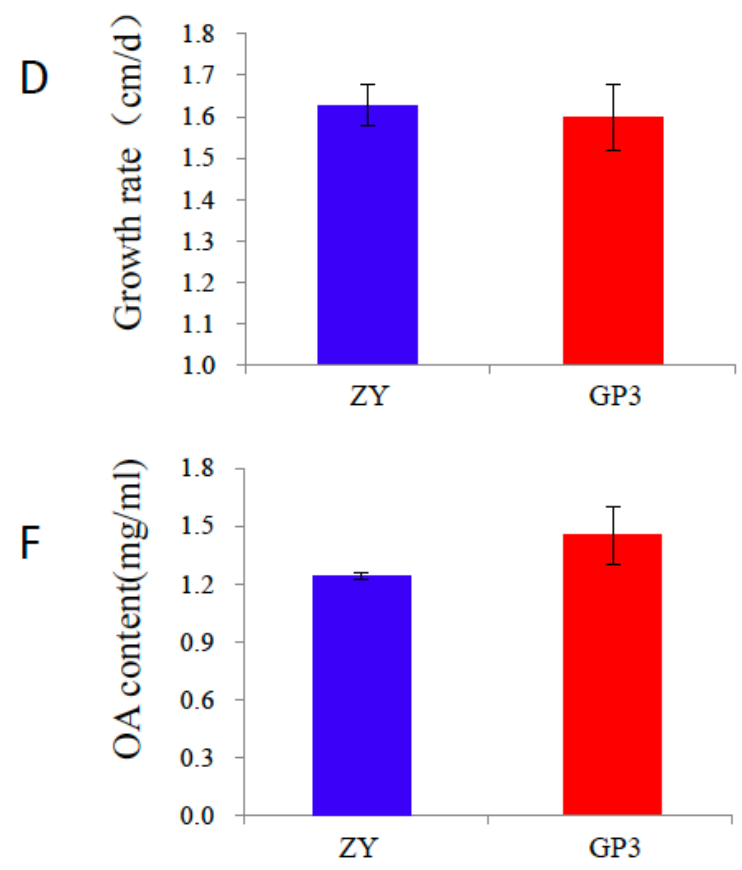

\section{Figure 1}

Disease index, growth rate, and Oxalic acid production of S. rolfsii GP3 and ZY. a Symptom of peanut caused by GP3 and ZY; b Disease index of GP3 and ZY; c Mycelium colony of GP3 and ZY; d Growth rate on the PDA plates, e Oxalic acid produced on PDA containing bromophenol blue; $\mathrm{f}$ Oxalic acid content in PDB medium. 


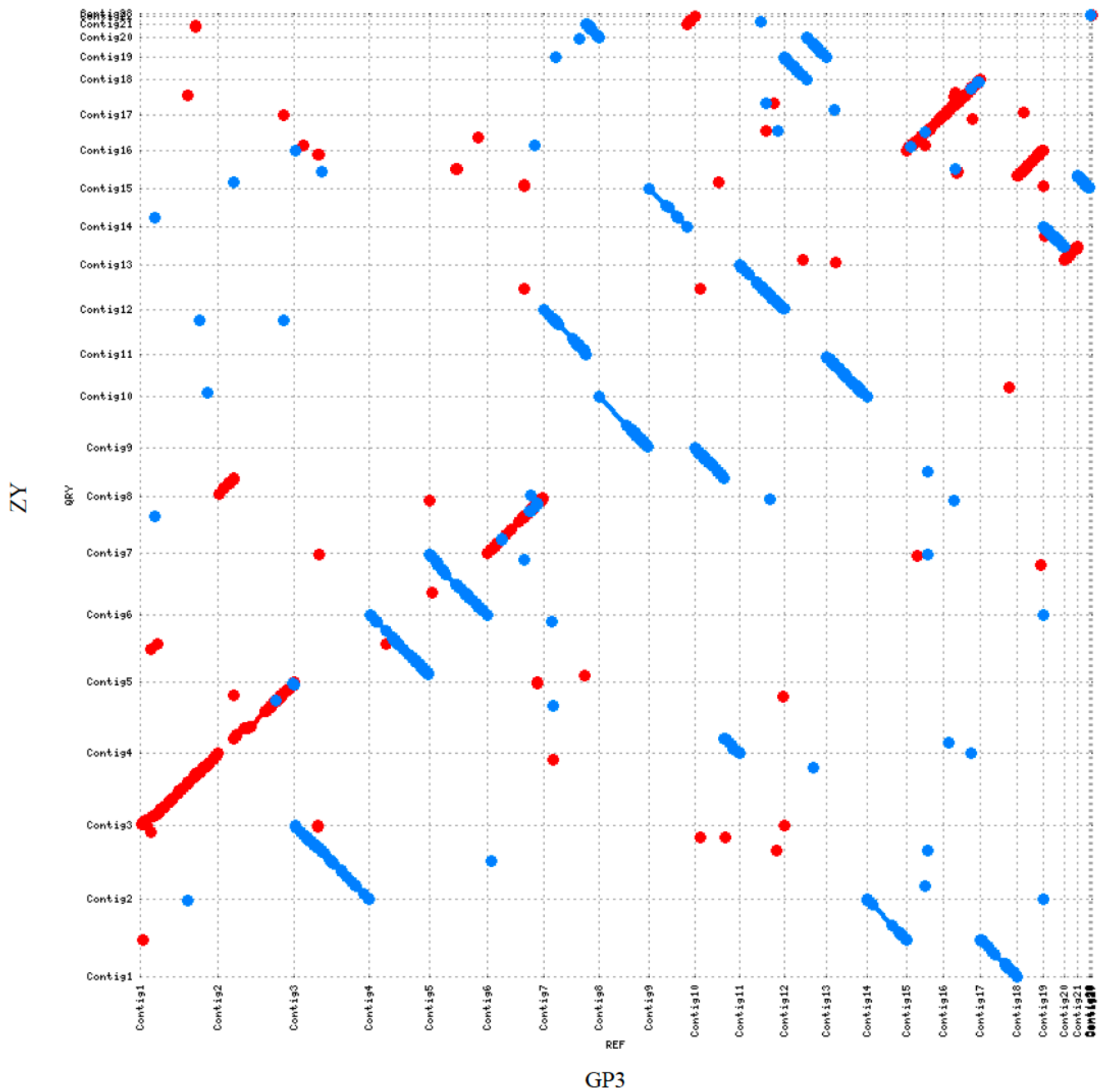

Figure 2

Genome synteny analysis between S. rolfsii strains GP3 and ZY. 


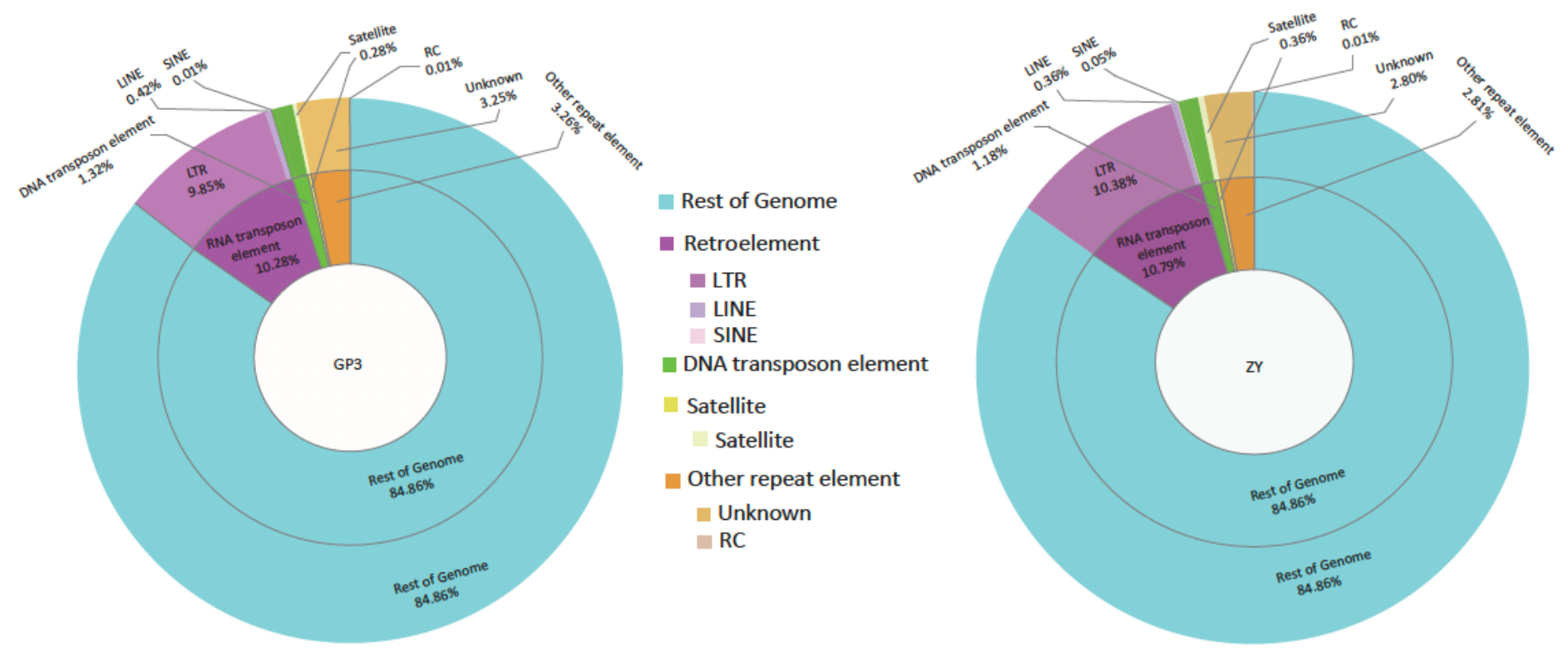

Figure 3

Distribution of repetitive sequences in S. rolfsii strains GP3 and ZY genomes.
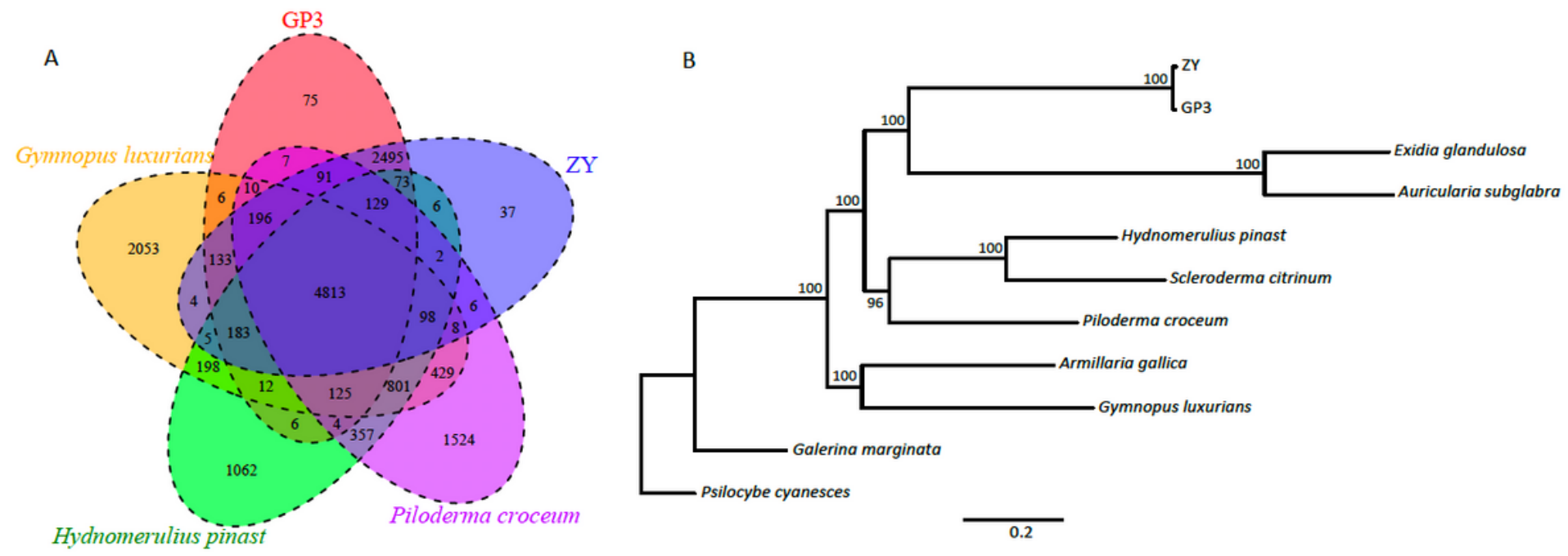

Figure 4

Phylogenetic and comparative genomic study of S. rolfsii GP3 and ZY. a Venn diagram showing an overlap of gene families among S. rolfsii GP3 and ZY, G. luxurians, P. croceum, and H. pinast; b Maximum likelihood phylogenetic tree of GP3 and ZY and nine fungi species in Agrariomycetes based on singlecopy orthologous genes, with Psilocybe cyanescens used as an outgroup species. 
A

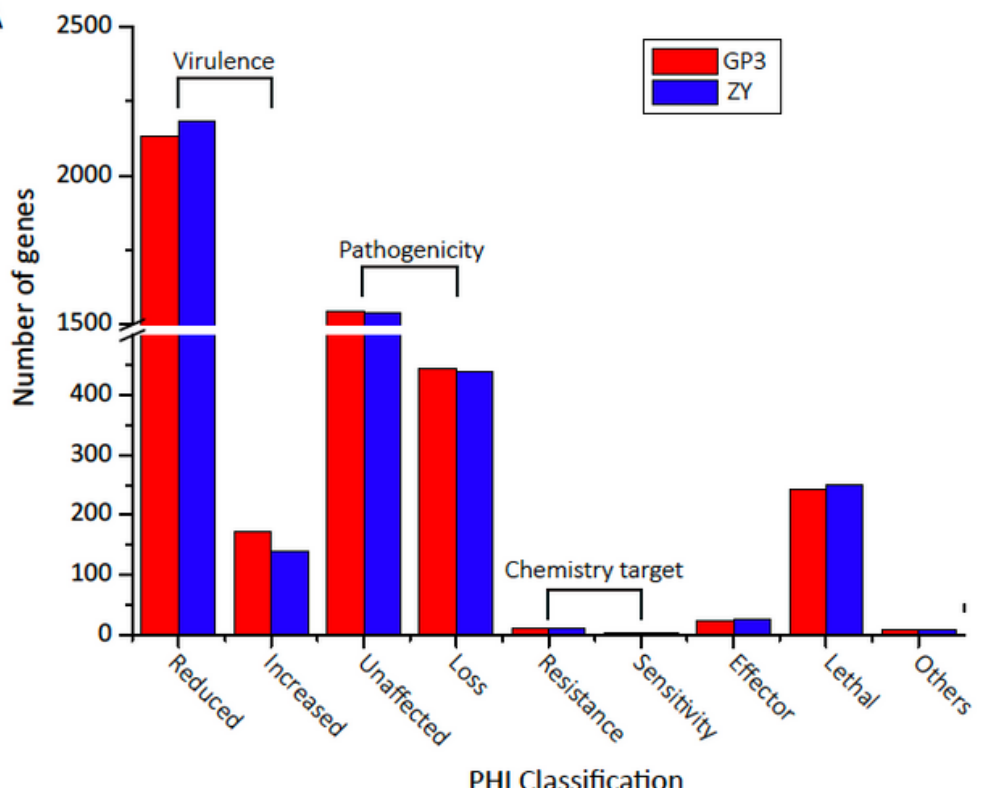

B

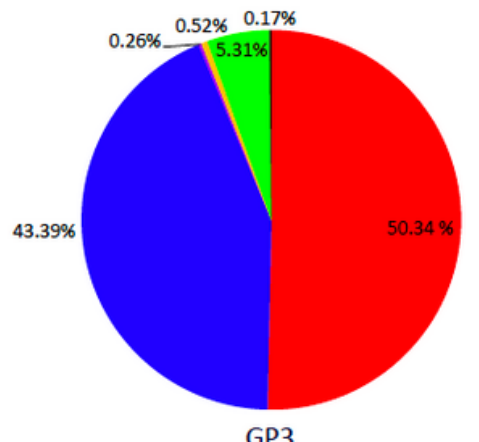

- Virulence

- Pathogenicity

Chemistry target

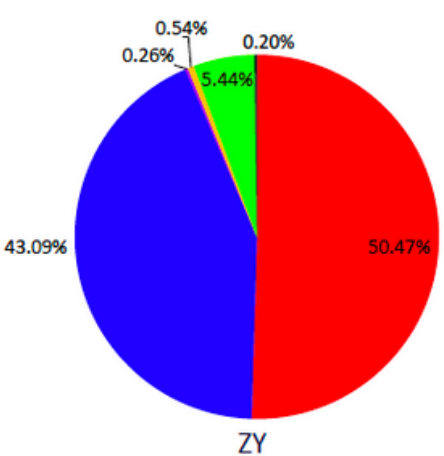

Effector

Lethal

Others

\section{Figure 5}

Pathogen-host interaction (PHI) genes of S. rolfsii GP3 and ZY. a Distribution of S. rolfsii PHI genes in different phenotypes; b Percentage of different phenotypes in total PHI genes of GP3 and ZY.

A

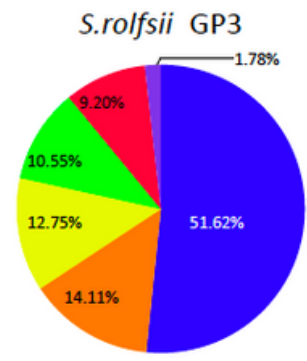

B

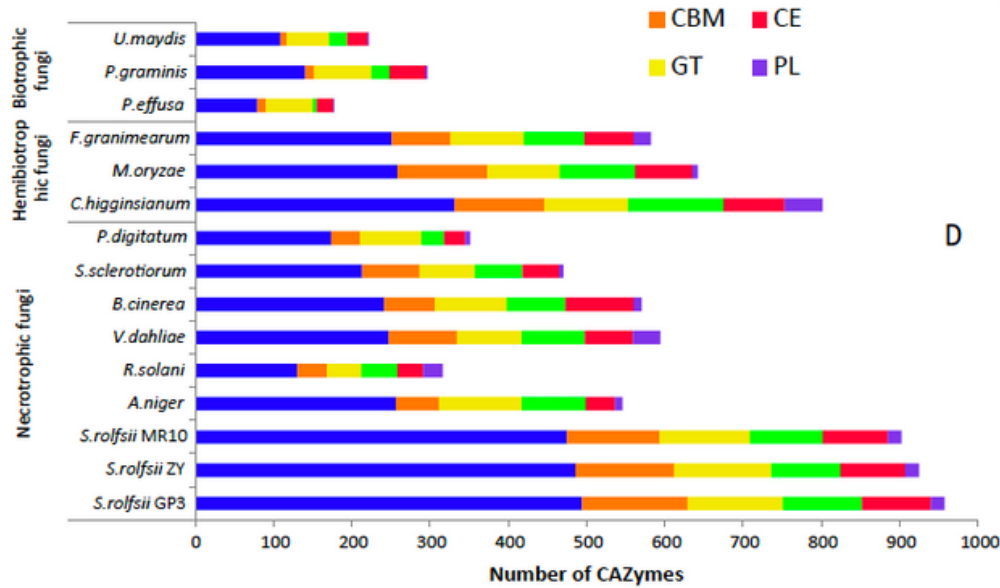

C
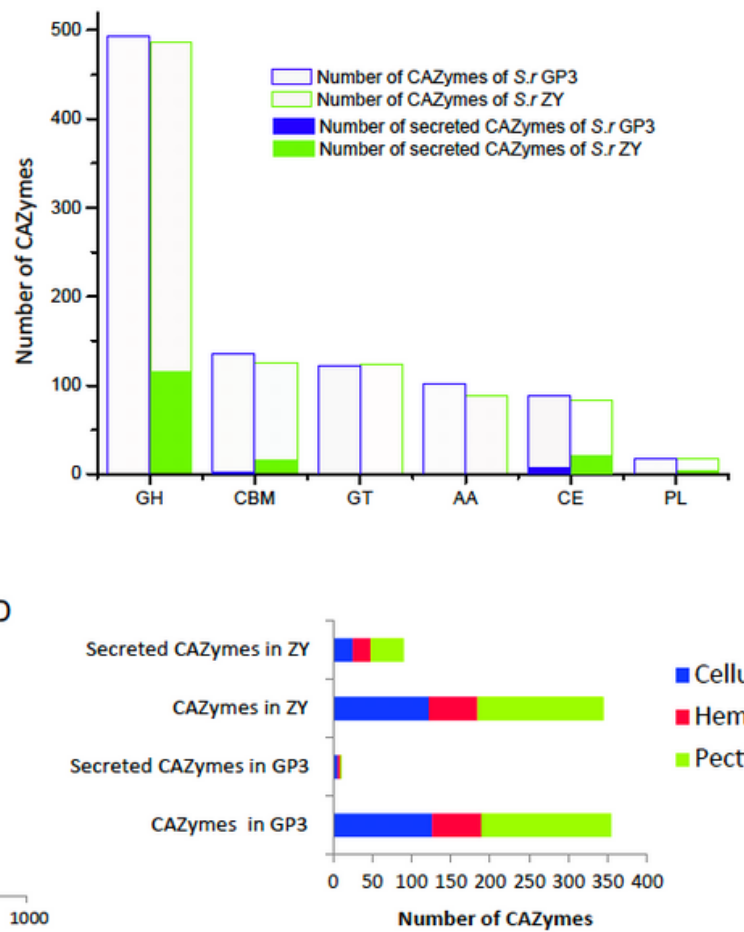

- Cellulose - Hemicellulose Pectin

Figure 6 
Distribution of CAZymes, secreted CAZymes, and CAZymes involved in plant cell wall degradation of $S$. rolfsii GP3 and ZY. a Distribution of CAZymes in S. rolfsii GP3 and ZY; b Comparison of CAZymes of S. rolfsii strains with other 12 plant pathogens; c Comparison of CAZymes and secreted CAZymes in GP3 and $Z Y$; d Comparison of CAzymes and secreted CAZymes involved in plant cell wall degradation in GP3 and ZY. GH: glycoside hydrolase, CBM: Carbohydrate-binding module, GT: Glycosyltransferase, AA: Auxiliary activity, CE: Carbohydrate esterase, PL: Polysaccharide lyase.

\section{Supplementary Files}

This is a list of supplementary files associated with this preprint. Click to download.

- Tables9.xlsx

- Figures7.pdf

- TableS8.xlsx

- TableS7.xIsx

- TableS6.xIsx

- TableS5.xlsx

- Figures6.pdf

- Tables4.xIsx

- TableS3.xlsx

- TableS2.xIsx

- TableS1.xlsx

- FigureS5.pdf

- Figures4.pdf

- Figures3.pdf

- Figures2.pdf

- FigureS1.pdf 